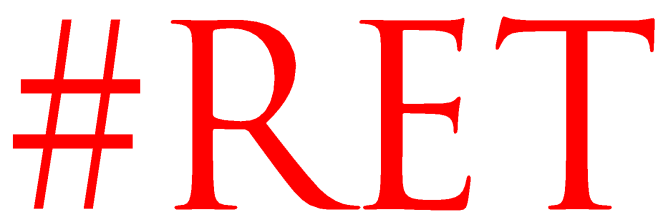

Revista Española de la Transparencia

Núm. 10. Primer Semestre 2020

ISSN 2444-2607. Págs. 65-96

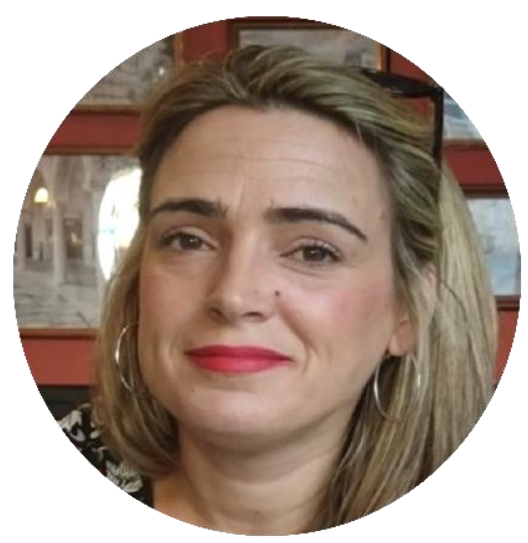

Esther Rando Burgos 1

Universidad de Málaga. España

\title{
Participación ciudadana y urbanismo: de los principios a la implementación 2
}

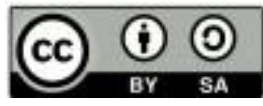

RECIBIDO: 2 de diciembre de 2019 ACEPTADO: 30 de enero de 2020

RESUMEN: La participación ciudadana en el urbanismo ha pasado de identificarse con el trámite preceptivo de información pública a tener autonomía en las diferentes legislaciones, generándose nuevos mecanismos que complementan y amplian los cauces de participación.

La ciudadanía se convierte en elemento fundamental en la conformación de los modelos urbanos, participando de manera activa en su definición. Las nuevas tecnologías, la transparencia, la gobernanza y la toma de consciencia del valor y el activo que representa la ciudadanía, conocedora de las debilidades y oportunidades de su pueblo o ciudad, se tornan en una realidad que vienen acogiendo algunas legislaciones urbanísticas. De la mera enunciación como principios, en los últimos tiempos comienzan a implementarse criterios y mecanismos concretos dirigidos al logro de una efectiva y real implicación de la ciudadanía en la concreción del modelo de pueblo o ciudad en el que aspira a vivir.

PALABRAS CLAVE: Urbanismo, participación ciudadana, información pública.

1 Doctora en Derecho por la Universidad de Málaga. Licenciada en Derecho y Licenciada en Ciencias del Trabajo por misma Universidad. Diplomada en Ordenación del Territorio y Máster en Regulación Económica y Territorial: especialidad Urbanismo, Ordenación del Territorio y Medio Ambiente. Profesora de Derecho Administrativo de la Universidad de Málaga (acreditada a PCD). Sus líneas de investigación se centran en el urbanismo, la ordenación del territorio y el medio ambiente, asi como en la jurisdicción contencioso-administrativa.

2 El presente artículo está basado en la ponencia que con idéntico título fue seleccionada para su presentación oral en el IV edición del Congreso Internacional de Transparencia y Acceso a la Información, celebrado en Málaga entre los días 30 de septiembre y 2 de octubre de 2019. 


\section{Esther Rando Burgos}

CONTENIDOS: 1.- INTRODUCCIÓN. 2.- PRECISANDO CONCEPTOS: INFORMACIÓN PÚBLICA Y PARTICIPACIÓN CIUDADANA. 2.1.- Información pública en la tramitación del planeamiento urbanístico. 2.2.- La información pública como medio de participación ciudadana en el urbanismo. 3.- PARTICIPACIÓN CIUDADANA EN LA CONFORMACIÓN DEL PLANEAMIENTO URBANÍSTICO. 3.1.- Marco general de referencia de la participación ciudadana. Especial referencia al urbanismo. 3.2.- La participación ciudadana en las legislaciones urbanísticas autonómicas. 3.3.- Los mecanismos para hacer efectiva y lograr una real participación ciudadana en la conformación del planeamiento urbanístico. 3.3.1.- Canarias: Programa de Participación Ciudadana. 3.3.2.- Cataluña: Programa de Participación Ciudadana y Consejo Asesor Urbanístico. 3.3.3.- Navarra: Plan de Participación. 3.3.4.- País Vasco: Programa de Participación Ciudadana y Consejo Asesor del Planeamiento. 3.3.5.Comunidad Valenciana: Plan de Participación Pública. 4.- CONCLUSIONES. BIBLIOGRAFÍA.

\section{Citizen participation and urbanism: from principles to implementation}

ABSTRACT: Citizen participation in urban planning has gone from identifying with the mandatory process of public information to having autonomy in the different legislations, generating new mechanisms that complement and expand the channels of participation.

Citizenship becomes a fundamental element in the shaping of urban models, actively participating in their definition. New technologies, transparency, governance and awareness of the value and asset of citizenship, aware of the weaknesses and opportunities of its people or city, become a reality that some laws have come with Urban. From the mere enunciation as principles, in recent times concrete criteria and mechanisms aimed at achieving an effective and real involvement of citizens in the definition of the town or city in which they aspire to live begin to be implemented.

KEYWORDS: Urban planning, citizen participation, public information. 


\section{Participación ciudadana y urbanismo}

\section{INTRODUCCIÓN}

Una de las cuestiones que cada vez emerge con mayor protagonismo en el urbanismo, pero también en otras funciones públicas, es la necesidad de una efectiva participación de la ciudadanía en los procedimientos de elaboración de los instrumentos, la llamada participación pública o, propiamente y siendo más concisos, participación ciudadana.

No es infrecuente tender a confundir participación ciudadana con información pública, y aunque cada vez está más definida y clara la diferencia entre ambos conceptos, no ha sido (ni sigue siendo) inusual emplearlos indistintamente. La información pública es un trámite preceptivo en el procedimiento de tramitación de los instrumentos, pero además «no es un mero trámite en el procedimiento de elaboración de los planes, sino un trámite esencial por la especial incidencia que tienen los mismos en la vida de los ciudadanos» ${ }^{3}$.

Por su parte, la participación ciudadana está cada día más presente en el conjunto de políticas públicas. Esta generalidad, se particulariza en el ámbito del urbanismo justificado por la especial incidencia que el modelo urbano definido desde la Administración tiene para la ciudadanía, lo que lleva a predicar cada vez con más fuerza una efectiva participación de aquélla en la concreción y definición del modelo urbano. Tanto es así que se instituye en uno de los cinco principios de la «buena gobernanza», recogido en el Libro Blanco de la Gobernanza.

En nuestro ordenamiento jurídico también se avanza en este sentido, y frente al derecho de audiencia y alegaciones que tradicionalmente viene integrando la fase de información pública de los instrumentos de planeamiento, cada vez está más presente, la participación ciudadana. Ilustrativa, sin duda, la exposición de motivos de la Ley 39/2015, de 1 de octubre, de Procedimiento Administrativo Común, entre otras, cuando señala «resulta esencial [...] la participación de los ciudadanos y empresas en los procesos de elaboración normativa, pues sobre ellos recae el cumplimiento de las leyes». Esta generalidad, se concreta con su positivización como derecho del ciudadano en el Real Decreto Legislativo 7/2015, de 30 de octubre, por el que se aprueba el texto refundido de la Ley de Suelo y Rehabilitación Urbana, TRLSRU, en coherencia con la previsión ya contenida con anterioridad en la Ley 8/2007, de 28 de mayo, de Suelo.

Pero además, nos encontramos ante competencias autonómicas, lo que obliga a acudir y poner en común los marcos legislativos en los que el urbanismo se desarrolla en nuestro país. Sólo de esta forma, estaremos en condiciones de conocer - y a la postre, valorar - la efectiva participación que en la configuración de nuestros pueblos y ciudades, viene reconociéndose desde el ordenamiento jurídico a la ciudadanía.

\footnotetext{
${ }^{3}$ Asi lo tiene reconocido el Tribunal Supremo, entre otras, en Sentencia del Tribunal Supremo, Sala de
} lo Contencioso, de 5 de mayo de 2015, núm. rec. 1559/2013. ECLI:ES:TS:2015:1839. 
Todo ello hace muy necesario el análisis de diversas cuestiones, centradas en el que es el objeto del presente trabajo, el urbanismo. En primer lugar, distinguir con nitidez entre información pública y participación ciudadana, tratando de clarificar lo obvio: la participación ciudadana hoy dia va más allá de la tradicional información pública. En segundo lugar, precisar la autonomía y sustantividad propia que nuestro ordenamiento jurídico reconoce a la participación ciudadana en la definición y concreción del urbanismo a través de la técnica del planeamiento. En tercer lugar, profundizando en lo anterior pero como necesario punto de partida, detenernos en lo que podría denominarse el presente de la participación ciudadana en el urbanismo, un presente en el que se observa cómo se da un paso adelante y se pasa de enunciar la participación ciudadana como principio de la actividad urbanística a la instauración de mecanismos concretos destinados a garantizarla, lo que puede coadyuvar a su logro.

Delimitado lo anterior y centrados en la participación ciudadana, el trabajo se enfoca en su articulación por las diferentes Comunidades Autónomas (particularizado en aquellas que más han avanzado en este sentido) a nivel normativo e incluso, en su caso, como se viene instrumentalizando el derecho de la ciudadanía a participar de manera real y efectiva en la definición, elaboración y tramitación de los instrumentos de planeamiento urbanístico.

\section{PRECISANDO CONCEPTOS: INFORMACIÓN PÚBLICA Y PARTICIPACIÓN CIUDADANA}

En nuestro ordenamiento jurídico ha sido tradicional regular en el marco de la legislación sobre procedimiento administrativo común, el trámite de información pública. Así lo recogía el artículo 86 de la hoy derogada Ley 30/1992, de 26 de noviembre, de Régimen Jurídico de las Administraciones Públicas y del Procedimiento Administrativo Común ${ }^{4}$ y lo hace hoy el artículo 83 de la Ley 39/2015, de 1 de octubre, del Procedimiento Administrativo Común de las Administraciones Públicas, en adelante LPAC, cuando señala:

\footnotetext{
4 Artículo 86 «Información pública» de la Ley 30/1992, de 26 de noviembre, de Régimen Jurídico de las Administraciones Públicas y del Procedimiento Administrativo Común: «1. El órgano al que corresponda la resolución del procedimiento, cuando la naturaleza de éste lo requiera, podrá acordar un periodo de información pública. 2. A tal efecto, se anunciará en el «Boletín Oficial del Estado», de la Comunidad Autónoma, o en el de la Provincia respectiva, a fin de que cualquier persona física o juridica pueda examinar el procedimiento, o la parte del mismo que se acuerde. El anuncio señalará el lugar de exhibición y determinará el plazo para formular alegaciones, que en ningún caso podrá ser inferior a veinte días. 3. La incomparecencia en este trámite no impedirá a los interesados interponer los recursos procedentes contra la resolución definitiva del procedimiento. La comparecencia en el trámite de información pública no otorga, por sí misma, la condición de interesado. No obstante, quienes presenten alegaciones u observaciones en este trámite tienen derecho a obtener de la Administración una respuesta razonada, que podrá ser común para todas aquellas alegaciones que planteen cuestiones sustancialmente iguales. 4. Conforme a lo dispuesto en las Leyes, las Administraciones Públicas podrán establecer otras formas, medios y cauces de participación de los ciudadanos, directamente o a través de las organizaciones y asociaciones reconocidas por la Ley en el procedimiento de elaboración de las disposiciones y actos administrativos».
} 


\section{Participación ciudadana y urbanismo}

«1. El órgano al que corresponda la resolución del procedimiento, cuando la naturaleza de éste lo requiera, podrá acordar un período de información pública.

2. A tal efecto, se publicará un anuncio en el Diario oficial correspondiente a fin de que cualquier persona física o jurídica pueda examinar el expediente, o la parte del mismo que se acuerde.

El anuncio señalará el lugar de exhibición, debiendo estar en todo caso a disposición de las personas que lo soliciten a través de medios electrónicos en la sede electrónica correspondiente, y determinará el plazo para formular alegaciones, que en ningún caso podrá ser inferior a veinte días.

3. La incomparecencia en este trámite no impedirá a los interesados interponer los recursos procedentes contra la resolución definitiva del procedimiento.

La comparecencia en el trámite de información pública no otorga, por sí misma, la condición de interesado. No obstante, quienes presenten alegaciones u observaciones en este trámite tienen derecho a obtener de la Administración una respuesta razonada, que podrá ser común para todas aquellas alegaciones que planteen cuestiones sustancialmente iguales.

4. Conforme a lo dispuesto en las leyes, las Administraciones Públicas podrán establecer otras formas, medios y cauces de participación de las personas, directamente o a través de las organizaciones y asociaciones reconocidas por la ley en el procedimiento en el que se dictan los actos administrativos».

Siguiendo a Alarcón Sotomayor «el trámite de información pública consiste en la exposición al público en general -no ya a los que sean interesado en ese procedimiento concreto- del contenido de un expediente administrativo que se está tramitando, con el fin de que pueda ser consultado y de que cualquier persona exprese su parecer sobre el objeto del mismo, formulando las alegaciones que estime convenientes (artículo 83.2 LPAC). Es un trámite facultativo, según prevé el artículo 83.1 LPAC, que algunas leyes sectoriales consagran como preceptivo para ciertos procedimientos administrativos concretos ${ }^{5}$.

\footnotetext{
5 Alarcón Sotomayor, L. 2017. «El procedimiento administrativo». En Rebollo Puig, M. y Vera Jurado, D. (dirs.) Derecho Administrativo. Tomo II, Rebollo Puig, M. y Carbonell Porras, E. (coords.) Régimen juridico básico y control de la Administración. Madrid: Editorial Tecnos, págs. 17-68 (págs. 54-55).
} 


\section{Esther Rando Burgos}

En efecto, el marco de referencia de la información pública se contiene en la LPAC. De interés resulta la ubicación en el cuerpo legal del artículo 83, dentro del capítulo IV «instrucción del procedimiento», en el marco del título IV «de las disposiciones sobre el procedimiento administrativo común» y de manera inmediata a los preceptos dedicados a regular la finalización del procedimiento (artículo 84 y ss.).

En la fase de instrucción del procedimiento, la LPAC distingue, además de las disposiciones generales dedicadas a los actos de instrucción y alegaciones (artículos 75 y 76), la prueba (artículos 77 y 78), informes (artículos 79 a 81) y por último, la participación de los interesados, que integra el trámite de audiencia (artículo 82) y la información pública (artículo 83).

Con carácter general, la información pública, según el tenor del artículo 83.1 LPAC, es un trámite facultativo en el procedimiento administrativo común, que dependerá de la naturaleza del procedimiento. Ahora bien, ello debe ser matizado toda vez que en determinados procedimientos administrativos, la información pública se prevé como trámite preceptivo por la correspondiente legislación especial. Es lo que ocurre, en lo que aqui ocupa, en los procedimientos de tramitación de planes urbanísticos ${ }^{6}$.

En relación con el modo en que ha de efectuarse, el artículo 83.2 LPAC, únicamente señala que «...se publicará un anuncio en el Diario oficial correspondiente a fin de que cualquier persona física o jurídica pueda examinar el expediente, o la parte del mismo que se acuerde». De igual forma, fija algunos requisitos que deben cumplirse, tales como, indicar el lugar de exhibición en que puede consultarse el expediente, la obligación de su puesta a disposición, para las personas que lo soliciten, a través de medios electrónicos en la sede electrónica que corresponda, y la fijación del plazo para formular alegaciones, sin que pueda ser inferior a veinte días.

También se ocupa la LPAC de indicar determinados efectos para el trámite de información pública. Por un lado, el artículo 83.3 LPAC señala que «la incomparecencia en este trámite no impide a los interesados interponer los recursos procedentes contra la resolución definitiva del procedimiento» a la vez que establece que el hecho de comparecer en el meritado trámite, no otorga, de facto, la condición de interesado en el procedimiento. Por otro, fija que «...quienes presenten alegaciones $u$ observaciones en este trámite tienen el derecho a obtener de la Administración una respuesta razonada, que podrá ser común para todas aquellas alegaciones que planteen cuestiones sustancialmente iguales» ${ }^{7}$.

\footnotetext{
6 Obra de referencia sobre la información pública desde una perspectiva conjunta es la de los profesores Fernández Ramos, S. y Pérez Monguió, J.M. 2017. El Derecho al Acceso a la Información Pública en España. Thomson Reuteurs Aranzadi.
}

7 Sobre el derecho de acceso a la información pública, vid, Razquin Lizarraga, M.M. 2015. El derecho de 


\section{Participación ciudadana y urbanismo}

\subsection{Información pública en la tramitación del planeamiento urbanístico.}

La información pública es un trámite preceptivo en el procedimiento de tramitación de los instrumentos de planeamiento urbanístico. La generalidad de personas a la que se dirige y la incidencia que en los mismos puede tener, justifican y hacen preciso este trámite. Abundando en lo anterior, la propia naturaleza de disposición de carácter general de los planes urbanísticos determina que su inobservancia tenga como consecuencia jurídica la nulidad de pleno derecho, con independencia de que la misma se deba a cuestiones formales, como la que nos ocupa, o materiales.

Ilustrativa, sin duda, la Sentencia del Tribunal Supremo de 5 de mayo de $2015^{8}$. cuando en su FD Decimoprimero, señala:

«...El trámite de información pública no es un mero trámite en el procedimiento de elaboración de los planes, sino un trámite esencial por la especial incidencia que tienen los mismos en la vida de los ciudadanos. Sin embargo dicho trámite no es el único posible, dado que la legislación urbanistica y medioambiental, cuenta con un cierto margen para determinar la forma concreta de garantizar la participación pública en el proceso de planeamiento en cumplimiento del art. $105 \mathrm{CE}$, por lo que no puede sostenerse que pueda prescindirse de alguno de los trámites, por el cumplimiento de otros, [...] aclarando que el cumplimiento de tal participación, no sólo no compromete, sino que refuerza el objetivo de protección que es la finalidad última de estos instrumentos de ordenación».

Coherente con ello, todas las legislaciones urbanísticas autonómicas, sin excepción, incorporan en el procedimiento de aprobación del planeamiento urbanístico el preceptivo trámite de información pública. Aunque en lo esencial se sigue un patrón común por todas las Comunidades Autónomas, por ejemplo en la tramitación del planeamiento general, es nota común la previsión de sometimiento a información pública del documento una vez tiene lugar la aprobación inicial del mismo, también se dan particularidades como el plazo que se confiere para el trámite de información pública o la forma en su publicidad.

A modo de resumen y con la finalidad de clarificar y ofrecer una perspectiva conjunta de la cuestión apuntada, se sintetiza en el siguiente cuadro las previsiones que en relación al trámite de información pública en el procedimiento de aprobación de los instrumentos de planeamiento general (en concreto, en los

acceso a la información pública: teoria y práctica, en especial, para las entidades locales. Guipuzkoa: Instituto Vasco de Administración Pública.

8 Sentencia del Tribunal Supremo, Sala de lo Contencioso, de 5 de mayo de 2015, núm. rec. 1559/2013. ECLI:ES:TS:2015:1839 


\section{TRÁMITE DE INFORMACIÓN PÚBLICA EN EL PROCEDIMIENTO DE APROBACIÓN DE INSTRUMENTOS DE PLANEAMIENTO URBANISTIICO GENERAL}

\begin{tabular}{|c|c|c|}
\hline CC.AA. y Normativa & $\begin{array}{l}\text { Momento y } \\
\text { Plazo }\end{array}$ & Publicidad \\
\hline $\begin{array}{l}\text { Andalucía: Ley } 7 / 2002 \text {, de } 17 \text { de diciembre, de Ordenación } \\
\text { Urbanística de Andalucía (art. } 32 \text { y 39) }\end{array}$ & $\begin{array}{l}\text { Tras Al9: } 1 \text { mes } \\
\text { (mínimo) }\end{array}$ & $\begin{array}{l}\text {-Boletín oficial que corresponda } \\
\text {-Un diario de mayor difusión provincial } \\
\text {-Tablón de anuncios municipal }\end{array}$ \\
\hline $\begin{array}{l}\text { Aragón: Decreto-Legislativo } 1 / 2014 \text {, de } 8 \text { de julio, del } \\
\text { Gobierno de Aragón, por el que se aprueba el texto } \\
\text { refundido de la Ley de Urbanismo de Aragón (art. 48) } \\
\text { Decreto } 52 / 2002 \text {, de } 19 \text { de febrero, del Gobierno de Aragón, } \\
\text { por el que se aprueba el Reglamento de desarrollo parcial } \\
\text { de la Ley } 5 / 1999 \text {, de } 25 \text { de marzo, Urbanística, en materia } \\
\text { de organización, planeamiento urbanístico y régimen } \\
\text { especial de pequeños municipios (art. } 62 \text { ) }\end{array}$ & $\begin{array}{l}\text { Avance: } 1 \text { mes } \\
\text { (mínimo) } \\
\text { Tras Al: } 2 \text { meses } \\
\text { (mínimo) }\end{array}$ & $\begin{array}{l}\text {-Boletín Oficial de Aragón } \\
\text {-Uno de los periódicos de mayor } \\
\text { circulación provincial }\end{array}$ \\
\hline $\begin{array}{l}\text { Asturias: Decreto Legislativo } 1 / 2004 \text {, de } 22 \text { de abril, texto } \\
\text { refundido disposiciones legales vigentes en materia de } \\
\text { Ordenación del Territorio y Urbanismo (art. 86) }\end{array}$ & $\begin{array}{l}\text { Tras Al: } 2 \text { meses } \\
\text { (mínimo) }\end{array}$ & $\begin{array}{l}\text {-Boletín Oficial Principado de Asturias } \\
\text {-Periódico de mayor difusión autonómica }\end{array}$ \\
\hline $\begin{array}{l}\text { Baleares: Ley } 12 / 2017 \text {, de } 29 \text { de diciembre, de Urbanismo } \\
\text { de las Illes Balears (arts. } 52 \text { y } 55 \text { ) }\end{array}$ & $\begin{array}{l}\text { Avance: } 1 \text { mes } \\
\text { (mínimo) } \\
\text { Tras Al: } 45 \text { días } \\
\text { (mínimo) }\end{array}$ & $\begin{array}{l}\text {-Boletín Oficial Islas Baleares } \\
\text {-Uno diarios de mayor circulación isla } \\
\text {-Sede electrónica Administración que lo } \\
\text { tramite }\end{array}$ \\
\hline $\begin{array}{l}\text { Canarias: Ley } 4 / 2017 \text {, de } 13 \text { de julio, del Suelo y de los } \\
\text { Espacios Naturales Protegidos de Canarias (arts. } 92.2 \text { y } \\
92.4 \text { ) }\end{array}$ & $\begin{array}{l}\text { Avance: } 45 \text { días } \\
\text { hábiles } \\
\text { (mínimo) / } 2 \\
\text { meses (máximo) } \\
\text { Tras Al: } 45 \text { días } \\
\text { hábiles } \\
\text { (mínimo) / } 3 \\
\text { meses (máximo) }\end{array}$ & $\begin{array}{l}\text {-Boletín Oficial de Canarias } \\
\text {-Dos de los periódicos de mayor difusión } \\
\text { de la isla } \\
\text {-Sede electrónica del Ayuntamiento } \\
\text {-Boletín Oficial de Canarias } \\
\text {-Dos de los periódicos de mayor difusión } \\
\text { de la isla } \\
\text {-Sede electrónica del Ayuntamiento }\end{array}$ \\
\hline $\begin{array}{l}\text { Cantabria: Ley } 2 / 2001 \text {, de } 25 \text { de junio, de Ordenación } \\
\text { Territorial y Régimen Urbanístico del Suelo de Cantabria } \\
\text { (artículo 68) }\end{array}$ & Tras Al: 1 mes & $\begin{array}{l}\text {-Boletín Oficial de Cantabria } \\
\text {-Al menos, en un periódico de difusión } \\
\text { regional }\end{array}$ \\
\hline $\begin{array}{l}\text { Castilla La Mancha: Decreto Legislativo } 1 / 2010 \text {, de } 18 \text { de } \\
\text { mayo, por el que se aprueba el texto refundido de la Ley de } \\
\text { Ordenación del Territorio y de la Actividad Urbanística (art. } \\
\text { 36) }\end{array}$ & $\begin{array}{lr}\text { Concluida } & \text { la } \\
\text { redacción } & \text { antes } \\
\text { Al: } \quad 1 & \text { mes } \\
\text { (mínimo) } & \end{array}$ & $\begin{array}{l}\text {-Diario Oficial de Castilla-La Mancha } \\
\text {-Uno de los periódicos de mayor difusión } \\
\text { autonómica }\end{array}$ \\
\hline $\begin{array}{l}\text { Castilla y León: Ley 5/1999, de } 8 \text { de abril, de Urbanismo de } \\
\text { Castilla y León (art. 52) }\end{array}$ & $\begin{array}{l}\text { Tras Al: De } 2 \text { a } 3 \\
\text { meses }\end{array}$ & $\begin{array}{l}\text {-Boletín Oficial de Castilla y León } \\
\text {-Uno de los diarios de mayor difusión en } \\
\text { la provincia } \\
\text {-Página web Ayuntamiento o, en su } \\
\text { defecto, en la página web de la } \\
\text { Diputación Provincial }\end{array}$ \\
\hline $\begin{array}{l}\text { Cataluña: Decreto Legislativo } 1 / 2010 \text {, de } 3 \text { de agosto, por el } \\
\text { que se aprueba el texto refundido de la Ley de Urbanismo } \\
\text { (art. 85) } \\
\text { Decreto } 305 / 2006 \text {, de } 18 \text { de julio, por el que se aprueba el } \\
\text { Reglamento de la Ley de Urbanismo (art. 23) }\end{array}$ & Tras Al: 1 mes & $\begin{array}{l}\text {-Diario oficial o boletín oficial que } \\
\text { corresponda } \\
\text {-Dos de los diarios de prensa periódica } \\
\text { de más divulgación en el ámbito } \\
\text { municipal o supramunicipal }\end{array}$ \\
\hline
\end{tabular}

\footnotetext{
${ }^{9}$ Aprobación inicial.
} 


\begin{tabular}{|c|c|c|}
\hline $\begin{array}{l}\text { C. Valenciana: Ley } 5 / 2014 \text {, de } 25 \text { de julio, de Ordenación } \\
\text { del Territorio, Urbanismo y Paisaje, de la Comunitat } \\
\text { Valenciana (art. 53) }\end{array}$ & $\begin{array}{l}\text { Versión inicial: } 45 \\
\text { días } \quad \text { hábiles } \\
\text { (mínimo) }\end{array}$ & $\begin{array}{l}\text {-Diario Oficial de la Comunidad } \\
\text { Valenciana } \\
\text {-Prensa escrita de gran difusión }\end{array}$ \\
\hline $\begin{array}{l}\text { Extremadura: Ley } 11 / 2018 \text {, de } 21 \text { de diciembre, de } \\
\text { Ordenación Territorial y Urbanística Sostenible de } \\
\text { Extremadura (arts. } 49 \text { y } 57 \text { ) }\end{array}$ & $\begin{array}{l}\text { Tras Al: } 45 \text { días } \\
\text { (mínimo) }\end{array}$ & $\begin{array}{l}\text {-Boletín oficial que corresponda } \\
\text {-Sede electrónica Administración } \\
\text { competente para la tramitación }\end{array}$ \\
\hline $\begin{array}{l}\text { Galicia: Ley 2/2016, de } 10 \text { de febrero, del Suelo de Galicia } \\
\text { (art. 60) }\end{array}$ & Tras Al: 2 meses & $\begin{array}{l}\text {-Diario Oficial de Galicia } \\
\text {-Uno de los periódicos de mayor difusión } \\
\text { de la provincia }\end{array}$ \\
\hline $\begin{array}{l}\text { La Rioja: Ley 5/2006, de } 2 \text { de mayo, de Ordenación del } \\
\text { Territorio y Urbanismo de La Rioja (art. 87) }\end{array}$ & Tras Al: 1 mes & $\begin{array}{l}\text {-Boletín Oficial de La Rioja } \\
\text {-Un diario de difusión local }\end{array}$ \\
\hline $\begin{array}{l}\text { Madrid: Ley 9/2001, de } 17 \text { de julio, del Suelo, de la } \\
\text { Comunidad de Madrid (arts. } 56,57 \text { y } 60 \text { ) }\end{array}$ & $\begin{array}{l}\begin{array}{l}\text { Avance: } 30 \text { días } \\
\text { (mínimo) }\end{array} \\
\begin{array}{l}\text { Tras Al: } 1 \text { mes } \\
\text { (mínimo) }\end{array}\end{array}$ & $\begin{array}{l}\text {-Boletín Oficial de la Comunidad de } \\
\text { Madrid }\end{array}$ \\
\hline $\begin{array}{l}\text { Navarra: Decreto Foral Legislativo } 1 / 2017 \text {, de } 26 \text { de julio, } \\
\text { por el que se aprueba el texto refundido de la Ley Foral de } \\
\text { Ordenación del Territorio y Urbanismo (art. 71). }\end{array}$ & $\begin{array}{l}\text { Versión } \\
\text { preliminar: } 1 \text { mes } \\
\text { (mínimo) } \\
\text { Tras Al: } 1 \text { mes } \\
\text { (mínimo) }\end{array}$ & $\begin{array}{l}\text {-Boletín Oficial de Navarra } \\
\text {-Diarios editados en la Comunidad Foral } \\
\text { de Navarra }\end{array}$ \\
\hline $\begin{array}{l}\text { País Vasco: Ley 2/2006, de } 30 \text { de junio, de Suelo y } \\
\text { Urbanismo (art. 90) }\end{array}$ & $\begin{array}{l}\text { Avance: } 2 \text { meses } \\
\text { (mínimo) } \\
\text { Tras Al: } 1 \text { mes }\end{array}$ & $\begin{array}{l}\text {-Boletín del Territorio Histórico } \\
\text {-Diario/s de mayor difusión o circulación } \\
\text { del territorio }\end{array}$ \\
\hline $\begin{array}{l}\text { Región de Murcia: Ley } 13 / 2015 \text {, de } 30 \text { de marzo, de } \\
\text { Ordenación Territorial y Urbanística de la Región de Murcia } \\
\text { (arts. } 155 \text { y 160) }\end{array}$ & $\begin{array}{l}\text { Avance: } 1 \text { mes } \\
\text { Tras Al: } 2 \text { meses } \\
\text { (mínimo) }\end{array}$ & $\begin{array}{l}\text {-Boletín Oficial de la Región de Murcia } \\
\text {-Sede electrónica del órgano que lo haya } \\
\text { acordado }\end{array}$ \\
\hline
\end{tabular}

Fuente: Elaboración propia a partir de las diferentes normativas urbanísticas autonómicas.

Precisamente este carácter esencial que se predica de la información pública en el urbanismo, unido al carácter reglamentario de los planes urbanísticos, tiene una nefasta consecuencia para el caso de no tener su debido cumplimiento: la nulidad de pleno derecho del plan. Ejemplos en este sentido no faltan, precisamente éste fue uno de los motivos que llevó en el año 2015 a que el Tribunal Supremo declarara la nulidad del Plan de Ordenación del Territorio de la Costa del Sol Occidental de la provincia de Málaga. Apuntaba el Alto Tribunal, en el FD Tercero de su Sentencia de 6 de octubre de $2015^{10}$, la importancia del trámite:

«En definitiva, como esta Sala del Tribunal Supremo ha declarado, entre otras, en sus Sentencias de fechas 25 de febrero de 2003 (recurso de casación 6876/1999), 16 de febrero de 2009 (recurso de casación 9414/2004) y 15 de marzo de 2012 (recurso de casación 6335/2008), la falta de respuesta a las alegaciones presentadas en el trámite de información pública equivale a la privación del derecho de audiencia, lo que supone la

10 Sentencia del Tribunal Supremo, Sala de lo Contencioso, de 6 de octubre de 2015, núm. rec. 2676/2012. ECLI:ES:TS:2015:4382. 


\section{Esther Rando Burgos}

omisión de un trámite esencial del procedimiento, ya que el exacto cumplimiento de dicho trámite de información pública requiere no sólo la mera formalización y recepción de las diversas alegaciones de los interesados sino su atenta lectura y contestación específica sobre las razones que lleven a la aceptación o rechazo de tales alegaciones, y exclusivamente asi cabe tener por cumplido el trámite de información pública destinado a posibilitar la participación pública en la elaboración del planeamiento requisitos formales que se omitieron en la tramitación y aprobación del Plan...».

Significativo como, en el tenor de la propia Sentencia, se refiere a información pública y participación ciudadana, en el sentido de que la información pública es un medio para alcanzar la participación ciudadana, quedando ambos interrelacionados.

\subsection{La información pública como medio de participación ciudadana en el urbanismo.}

En la elaboración y tramitación de los planes urbanísticos, la información pública tiene el carácter de participación ciudadana, así ha sido y viene siendo considerado conforme a una prolija jurisprudencia tanto del Tribunal Constitucional como del propio Tribunal Supremo. Si bien se busca destacar como de manera progresiva algunas legislaciones urbanísticas vienen generando nuevos mecanismos de participación ciudadana distintos o complementarios de la tradicional información pública en este ámbito, lo que se entiende esencial para el logro de una efectiva participación ciudadana, ello no obvia que este trámite procedimental constituya un cauce de participación ciudadana, el medio tradicionalmente empleado para su consecución. Ello justifica que el punto de partida se centre, precisamente, en una aproximación a la información pública como medio de participación ciudadana en el ámbito del urbanismo.

La Sentencia del Tribunal Constitucional, en adelante STC, 119/1995, de 17 de julio $^{11}$, particularmente en su FJ 6, invoca la existencia de un tercer género de democracia, denominada democracia participativa, en torno a la que califica como «...una participación en la actuación administrativa, de carácter funcional o procedimental, que garantiza tanto la corrección del procedimiento cuanto los derechos e intereses legítimos de los ciudadanos...» y que «...no estamos ante cauces articulados para conocer la voluntad de la generalidad de los ciudadanos en los distintos ámbitos en que territorialmente se articula el Estado- precisamente en lo que tiene de general, sino más bien para oír, en la mayor parte de los casos, la voz de intereses sectoriales de indole económica, profesional, etc. Se trata de manifestaciones que no son propiamente encuadrables ni en las formas de

11 BOE núm. 200, de 22 de agosto de 1995. 


\section{Participación ciudadana y urbanismo}

democracia representativa en las de democracia directa, incardinándose más bien en un tertirum genus que se ha denominado democracia participativa $>^{12}$.

A mayor abundamiento, y en el plano que ocupa, la meritada Sentencia afirma que «... En el ámbito de los planes urbanísticos la participación de los ciudadanos se realiza a través del trámite de información pública, que ha sido caracterizado por el Tribunal Supremo como forma de instrumentar su legitimación democrática» ${ }^{13}$. No en vano, el trámite de información pública no se circunscribe a los ciudadanos afectados, titulares de derechos e intereses legítimos, como ocurre en el trámite de audiencia, sino que abarca a éstos y a cualquier ciudadano que quiera formular alegaciones al respecto. Precisamente, esta particularidad lleva a que se haya destacado que el trámite de información pública está informado por el principio general de audiencia al interesado, más amplio que el trámite de audiencia. Autores como Tardío Pato mantienen el carácter de principio general de audiencia, destacando que «lgualmente, están inspirados en el principio general de audiencia el trámite de información pública del artículo 86 de la Ley 30/1992 y el trámite de información pública del artículo 24.1.c) de la Ley 50/1997, de 26 de noviembre, del Gobierno (este último, en relación con el procedimiento de elaboración de los reglamentos), sin perjuicio de que también estén vinculados al principio de participación ciudadana en los asuntos públicos consagrado en el artículo 9.2 de la Constitución $\gg^{14}$.

El interés de esta Sentencia radica en el reconocimiento de que el trámite de información pública en el procedimiento para la aprobación de planes urbanísticos tiene una vertiente de participación ciudadana, como forma de participación en la actuación administrativa, de carácter funcional o procedimental, de la que se hace eco la propia resolución judicial.

Este tipo de participación se caracteriza, como puntualiza la STC 28/2017, de 16 de febrero ${ }^{15}$, en su FJ 6, porque «...lo decisivo es que la Administración decida con plena libertad, pero a la luz de las alegaciones de los ciudadanos». Por ello, se ha resaltado que el criterio diferenciador que puede dar sentido a la distinción entre

12 Sobre el particular, vid. García Macho, R. 2011. «La participación ciudadana en la ordenación urbanística y admisión de proyectos de obras públicas». En Sánchez Blanco, Á., Domínguez- Berrueta de Juan, M.A., Rivero Ysern, J.L. (coords.). El nuevo derecho administrativo: libro homenaje al Profesor Dr. Enrique Rivero Ysern. Salamanca: Ratio Legis Librería Juridica, págs. 179-185.

13 Esta vertiente, además de por la Sentencia indicada, ha sido destacada por autores como Tolivar Alas, L. 2010. «Principio de participación». En Santamaria Pastor, J.A. (dir.) Los principios jurídicos del derecho administrativo. Madrid: Editorial La Ley, págs. 945-979 (pág. 966).

14 Tardio Pato, J.A. 2006. «El principio constitucional de audiencia del interesado y el trámite del artículo 84 de la Ley 30/1992». Revista de Administración Pública, núm. 170, págs. 93-142. Del mismo autor, de interés sobre el particular, 2017. «Alegaciones, audiencia y participación y de los interesados». En Fernández Ramos, S., Valero Torrijos, J. y Gamero Casado, E. (dirs.) Tratado de Procedimiento Administrativo Común y Régimen Jurídico Básico del Sector Público. Valencia: Editorial Tirant lo Blanch, págs. 1554-1638.

15 BOE núm. 72, de 25 de marzo de 2017. 
democracia directa y este tercer género, calificado como democracia participativa, es, precisamente, el carácter vinculante, al menos a nivel de propuesta. Mientras en la participación directa, la intervención de la ciudadanía tiene carácter vinculante, en la intervención participativa no posee tal carácter, sino que simplemente se pretende conocer el sentir de la misma, su opinión, antes de adoptarse la decisión última por los órganos competentes ${ }^{16}$.

En sintesis, pese a la evolución que la participación ciudadana en el ámbito urbanístico viene teniendo en las recientes legislaciones promulgadas, particularmente en las de ciertas Comunidades Autónomas, que contemplan una participación ciudadana que no sólo gira en torno al trámite de información pública sino a través de otros mecanismos que serán analizados más adelante, se ha de partir del propio carácter de participación ciudadana que los trámites de información pública tienen en la elaboración y tramitación de los instrumentos de planeamiento urbanístico.

\section{PARTICIPACIÓN CIUDADANA EN LA CONFORMACIÓN DEL PLANEAMIENTO URBANÍSTICO}

El planeamiento urbanístico se encarga de concretar un modelo de ciudad, la ciudad en la que habitará la ciudadanía y para ello se ejercitan potestades discrecionales por parte del planificador municipal. Precisamente, esta aparente amplia discrecionalidad, y sin perjuicio de las limitaciones de las diferentes legislaciones y planificaciones sectoriales que inciden y la condicionan, se trata de compensar por nuestro ordenamiento jurídico a través de la motivación.

Pero la elevada repercusión que la elección de un u otro modelo va a tener sobre la ciudadanía, hace adecuado y preciso que la misma forme parte del proceso previo en el que se decide, se dibuja y se concreta el modelo de ciudad. La técnica para ello es la puesta en marcha de auténticos mecanismos dirigidos a la participación ciudadana que no sólo ha de instituirse en principio inspirador sino materializarse mediante herramientas concretas. Como ya apuntáramos «Tan importante [...], resulta una efectiva y real participación pública, es fundamental que tanto los agentes sociales y económicos implicados, como la ciudadanía en general sean parte y, sobre todo, se sientan parte, del proyecto [...]. Al fin y al cabo hay una realidad patente que a menudo parece olvidarse, serán ellos los destinatarios y protagonistas finales de las propuestas y actuaciones que alli se contienen, quienes disfruten y se beneficien de su éxito o padezcan su fracaso y

16 Tardio Pato, J.A. 2019. «Comentario al artículo 43, de la Ley Valenciana 2/2015». En Díez Sánchez, J.J. y García Macho, R. (coords.) Comentarios a la Ley 2/2015, de 2 de abril, de Transparencia, Buen Gobierno y Participación Ciudadana en la Comunitat Valenciana. Madrid: Editorial Reus, pág. 314. Ya antes, Tardío Pato, J.A. 2018. «Los límites al principio de la mayoría no sólo derivados del Estado de Derecho sino también del propio Estado Democrático: la denominada Ley catalana de autodeterminación como ejemplo». Revista Española de Derecho Administrativo, núm. 189, págs. 93126. 


\section{Participación ciudadana y urbanismo}

conforman un elemento fundamental en el modelo territorial previsto: la población del instrumento ${ }^{17}$.

\subsection{Marco general de referencia de la participación ciudadana. Especial referencia al urbanismo.}

La participación ciudadana tiene autonomía y sustantividad propia, tratándose de una cuestión que va más allá de un mero trámite y así lo reconoce nuestro ordenamiento jurídico.

El propio artículo 9.2. de la Constitución Española, en adelante CE, encomienda, con carácter general, a los poderes públicos la obligación de «...promover las condiciones para facilitar la participación de todos los ciudadanos en la vida política, económica, cultural y social». O de manera más precisa, el artículo 105.a) de la CE que reconoce «La audiencia de los ciudadanos, directamente o a través de las organizaciones y asociaciones reconocidas por la ley, en el procedimiento de elaboración de las disposiciones administrativas que les afecten».

La propia LPAC se hace eco de la cada vez más imperante importancia de la participación ciudadana, y junto a los ya señalados trámites de audiencia e información pública, como garantes de la participación del interesado en el procedimiento administrativo, dedica su último precepto, el artículo 133, a lo que denomina «participación de los ciudadanos en el procedimiento de elaboración de normas con rango de Ley y reglamentos», previendo que «Con carácter previo a la elaboración del proyecto o anteproyecto de ley o reglamento, se sustanciará una consulta pública», salvo los supuestos recogidos en el aptdo. 4 del propio artículo 133, en los que podrá prescindirse de dicho trámite, ceñidos a las «...normas presupuestarias u organizativas de la Administración General del Estado, la Administración autonómica, la Administración local o de las organizaciones dependientes o vinculadas a éstas, o cuando concurran razones graves de interés público que lo justifiquen $\gg^{18}$.

\footnotetext{
17 Rando Burgos, E. 2020. Régimen Jurídico de la Gestión Territorial. Valencia: Editorial Tirant lo Blanch (pág. 60).

18 Este precepto, en su redacción originaria, disponía que: «1. Con carácter previo a la elaboración del proyecto o anteproyecto de ley o de reglamento, se sustanciará una consulta pública, a través del portal web de la Administración competente en la que se recabará la opinión de los sujetos y de las organizaciones más representativas potencialmente afectados por la futura norma acerca de: a) Los problemas que se pretenden solucionar con la iniciativa. b) La necesidad y oportunidad de su aprobación. c) Los objetivos de la norma. d) Las posibles soluciones alternativas regulatorias y no regulatorias. 2. Sin perjuicio de la consulta previa a la redacción del texto de la iniciativa, cuando la norma afecte a los derechos e intereses legítimos de las personas, el centro directivo competente publicará el texto en el portal web correspondiente, con el objeto de dar audiencia a los ciudadanos afectados y recabar cuantas aportaciones adicionales puedan hacerse por otras personas 0 entidades. Asimismo, podrá también recabarse directamente la opinión de las organizaciones o asociaciones reconocidas por ley que agrupen o representen a las personas cuyos derechos o intereses legítimos se vieren afectados por la norma y cuyos fines guarden relación directa con su objeto. 3. La consulta, audiencia e información públicas reguladas en este artículo deberán realizarse
} 


\section{Esther Rando Burgos}

Por su parte, el Texto Refundido de la Ley del Suelo y Rehabilitación Urbana, para sucesivas menciones TRLSRU, aprobado por Real Decreto Legislativo 7/2015, de 30 de octubre, al enumerar los derechos de los ciudadanos en su artículo 5. reconoce su letra e), el relativo a:

«Participar efectivamente en los procedimientos de elaboración y aprobación de cualesquiera instrumentos de ordenación del territorio o de ordenación y ejecución urbanísticas y de su evaluación ambiental mediante la formulación de alegaciones, observaciones, propuestas, reclamaciones y quejas y a obtener de la Administración una respuesta motivada, conforme a la legislación reguladora del régimen jurídico de dicha Administración y del procedimiento de que se trate».

Particular mención requiere el meritado precepto. En primer lugar, se está ante «derechos del ciudadano» ${ }^{19}$, enmarcados en lo que el cuerpo legal denomina «estatuto básico del ciudadano». En segundo lugar, se refiere expresamente a dos momentos diferenciados en los que debe tener lugar dicha participación efectiva, lo que debe ponerse en adecuada relación con el carácter bifásico de los instrumentos de planeamiento urbanístico, tanto en la elaboración como en la aprobación, frente a la información pública que se integra en el procedimiento de tramitación. En tercer lugar, es clarificador en la forma en la que llevar a cabo dicha participación efectiva, así señala modos como «la formulación de alegaciones, observaciones propuestas, reclamaciones y quejas». En cuarto y último lugar, no sólo recoge el derecho a formular las mismas en ejercicio del derecho reconocido

de forma tal que los potenciales destinatarios de la norma y quienes realicen aportaciones sobre ella tengan la posibilidad de emitir su opinión, para lo cual deberán ponerse a su disposición los documentos necesarios, que serán claros, concisos y reunir toda la información precisa para poder pronunciarse sobre la materia. 4. Podrá prescindirse de los trámites de consulta, audiencia e información públicas previstos en este artículo en el caso de normas presupuestarias u organizativas de la Administración General del Estado, la Administración autonómica, la Administración local o de las organizaciones dependientes o vinculadas a éstas, o cuando concurran razones graves de interés público que lo justifiquen. Cuando la propuesta normativa no tenga un impacto significativo en la actividad económica, no imponga obligaciones relevantes a los destinatarios o regule aspectos parciales de una materia, podrá omitirse la consulta pública regulada en el apartado primero. Si la normativa reguladora del ejercicio de la iniciativa legislativa o de la potestad reglamentaria por una Administración prevé la tramitación urgente de estos procedimientos, la eventual excepción del trámite por esta circunstancia se ajustará a lo previsto en aquella». No obstante, la Sentencia 55/2018, de 24 de mayo, del Tribunal Constitucional, resolviendo el recurso de inconstitucionalidad 3628/2016, interpuesto por el Gobierno de la Generalitat de Cataluña en relación con diversos preceptos de la LPAC (BOE núm. 151, de 22/06/2018), declara contrario al orden constitucional de competencias, diversos preceptos, entre ellos el art. 133, salvo el inciso de su apartado primero «Con carácter previo a la elaboración del proyecto o anteproyecto de ley o de reglamento, se sustanciará una consulta pública» y el primer párrafo de su apartado 4.

19 Sobre la transparencia y la participación ciudadana introducidas por la Ley de Suelo de 2007 como antídotos contra la corrupción, tiene especial relevancia el trabajo de Ponce Solé, J. y Capdeferro Villagrasa, Ó. 2017. «Buen gobierno urbano, transparencia y participación ciudadana». En VAQUER CABALLERIA, M. Ejemplar dedicado a: La ley estatal de suelo, 10 años después. Práctica urbanistica. Revista mensual de urbanismo, núm. 146. 
sino que genera la consiguiente obligación para la Administración de dar una respuesta a las mismas que además habrá de ser motivada ${ }^{20}$.

\subsection{La participación ciudadana en las legislaciones urbanísticas autonómicas.}

En coherencia con lo indicado, la tendencia generalizada seguida por las diferentes Comunidades Autónomas es incorporar expresamente la participación ciudadana en sus correspondientes legislaciones, al margen de las previsiones concretas, ya señaladas, dirigidas a dar debido cumplimiento al trámite de información pública en la tramitación de sus instrumentos de planeamiento urbanístico ${ }^{21}$.

En este sentido, de la puesta en común de los diecisiete marcos normativos autonómicos, resultan diferencias palpables. Así, mientras Comunidades Autónomas como Cantabria ${ }^{22}$ no contiene referencia expresa a la participación ciudadana en su marco legislativo, otras como Castilla-La Mancha muestran una tendencia más general al centrarse en la participación de los sujetos privados en la actividad urbanística ${ }^{23}$ o Castilla y León que, de similar manera, se refiere a lo que denomina participación social, encomendando de igual forma a las Administraciones el promover la más amplia participación social, garantizando el derecho de información ${ }^{24}$.

Otras Comunidades Autónomas optan por incorporar la participación ciudadana entre los principios y fines de la ordenación urbanística. Es el caso de Madrid ${ }^{25}$, Aragón $^{26}$, Extremadura ${ }^{27}$ o Galicia ${ }^{28}$.

20 Sin obviar los conflictos que en su aplicación práctica, en ocasiones, tienen lugar. En este sentido se pronuncia Mozo Amo, J. 2015. «El urbanismo y la participación ciudadana». Encuentros multidisciplinares, Vol. 17, núm. 50. Ejemplar dedicado a: Urbanismo y Organización del Territorio en Clave Multidisciplinar, págs. 23-30.

21 Sobre la participación ciudadana en el urbanismo, vid, Chinchilla Peinado, J.A. 2016. «La participación ciudadana en el urbanismo: ¿mito o realidad?». En Gifreu i Font, J., Bassols Coma, M. y Menéndez Rexach, Á. (dirs.) El derecho a la ciudad y el territorio: estudios en homenaje a Manuel Ballbé Prunés. Madrid: Instituto Nacional de Administración Pública, págs. 232-246.

22 Ley 2/2001, de 25 de junio, de Ordenación Territorial y Régimen Urbanístico del Suelo de Cantabria.

23 Artículo 8 «La participación de los sujetos privados en la actividad administrativa urbanística» del Decreto Legislativo 1/2010, de 18 de mayo, por el que se aprueba el texto refundido de la Ley de Ordenación del Territorio y de la Actividad Urbanística..

24 Artículo 6 «Participación social» de la Ley 5/1999, de 8 de abril, de Urbanismo de Castilla y León.

25 Artículo 3 «Principios rectores y fines de la ordenación urbanística» de la Ley 9/2001, de 17 de julio, del Suelo, de la Comunidad de Madrid, enuncia en su apartado 1, letra d):

«1. Son principios rectores de la ordenación urbanística: [...] d) El de participación ciudadana. En la formulación, gestión y ejecución de la actividad urbanística, la Comunidad de Madrid y los Ayuntamientos deberán fomentar e impulsar la participación, así como velar por los derechos de iniciativa e información de los ciudadanos y de las entidades que les representan. A tal efecto, garantizarán el acceso de los ciudadanos, en los términos legalmente establecidos, a los documentos 


\section{Esther Rando Burgos}

Sin embargo, la tendencia mayoritaria observada, es la ubicación de la participación ciudadana como precepto autónomo en el marco de las disposiciones de carácter general. Este es el criterio empleado, sin carácter

que integran los instrumentos de planeamiento y ejecución, durante el proceso de su redacción y con posterioridad a su aprobación».

26 Artículo 3 «Principios», letra e) del Decreto-Legislativo 1/2014, de 8 de julio, del Gobierno de Aragón, por el que se aprueba el texto refundido de la Ley de Urbanismo de Aragón: «La actividad urbanística se desarrollará para la consecución de los objetivos establecidos en el artículo siguiente conforme a los siguientes principios: [...] e) Participación ciudadana, habilitando en los procedimientos para la adopción de decisiones urbanísticas los trámites de información y audiencia pública en los términos establecidos en las leyes».

27 La Ley 11/2018, de 21 de diciembre, de Ordenación Territorial y Urbanística Sostenible de Extremadura, se refiere a la participación ciudadana como principio general. $Y$ lo hace en dos momentos, en la propia exposición de motivos y en el articulado. De esta forma, la exposición de motivos señala: «En atención a lo expuesto, los principios generales que aborda este texto normativo son los siguientes: a) Participación ciudadana. Se configura como obligación el posibilitar la participación ciudadana desde el inicio de la elaboración de los instrumentos de ordenación, debiendo justificarse las acciones y relaciones participativas realizadas, así como las conclusiones y su integración en los planes. El empoderamiento de la ciudadanía debe ser irreversible, como elemento enriquecedor e imprescindible en la definición de nuestros modelos urbanos y en su gestión responsable. Se trata de reivindicar el derecho a la ciudad como derecho fundamental». Por su parte, el art. 2 «Principios generales y fines de la ordenación territorial y urbanística», en su apartado 1, letra e), establece: «1. Los principios en los que debe basarse toda actuación en relación con la ordenación territorial y urbanística son: [...] e) La garantía de que la actividad de ordenación territorial y urbanística se desarrolle conforme a las necesidades de la sociedad promoviendo una amplia y efectiva participación ciudadana y garantizando los derechos de información e iniciativa de las personas y de las entidades constituidas para la defensa de sus intereses».

28 Artículo 5 «Fines de la actividad urbanística» de la Ley 2/2016, de 10 de febrero, del Suelo de Galicia, señala en su letra f): «La actividad administrativa en materia de urbanismo tendrá, en aplicación de los principios constitucionales de la política económica y social, entre otras, las siguientes finalidades: [...] f) Velar para que la actividad urbanistica se desarrolle promoviendo la más amplia participación social, garantizando los derechos de información y de iniciativa de los particulares, asegurando, en todo caso, la participación de los ciudadanos y asociaciones por estos constituidas para la defensa de sus intereses y valores». 


\section{Participación ciudadana y urbanismo}

exhaustivo, por Andalucia ${ }^{29}$, Asturias $^{30}$, La Rioja $^{31}$, Murcia $^{32}$, Navarra $^{33}$, País Vasco $^{34}$ o Comunidad Valenciana ${ }^{35}$.

Todo ello, sin perjuicio, en ocasiones, de otras referencias específicas que se contienen en las propias legislaciones indicadas y que son objeto de análisis a continuación.

\subsection{Los mecanismos para hacer efectiva y lograr una real participación ciudadana en la conformación del planeamiento urbanístico.}

Por último, es esencial detenerse en el avance que para la efectiva implementación de la participación ciudadana en los procedimientos de elaboración de instrumentos urbanisticos se viene produciendo. Aunque, por el momento, de manera muy concreta y sólo en algunas Comunidades Autónomas, anima observar como se viene dando un paso adelante en este sentido. Se advierte como la participación ciudadana evoluciona pasando de enunciarse como principio inspirador de la actividad urbanística, incluso como derecho de información, al establecimiento de mecanismos concretos destinados, en efecto, a garantizarla y lograrla.

Entendemos que esta cuestión es fundamental, no debe olvidarse que al fin y al cabo un plan urbanístico no recoge más que un modelo de ciudad, se dibuja en un plano un modelo de futuro y es aquí, en este momento, donde debe tener lugar esa efectiva participación ciudadana, de poco sirve que una vez que el modelo está definido y concretado, incluso el plan se encuentra en tramitación darlo a conocer a la ciudadanía. La verdadera participación ciudadana debe tener lugar en un momento muy anterior, la ciudadanía debe estar imbricada desde el preciso

29 Artículo 6 «La participación ciudadana» de la Ley 7/2002, de 17 de diciembre, de Ordenación Urbanística de Andalucía.

30 Artículo 7 «Participación ciudadana» del Decreto Legislativo 1/2004, de 22 de abril, por el que se aprueba el texto refundido de las disposiciones legales vigentes en materia de Ordenación del Territorio y Urbanismo.

31 Artículo 10 «Participación ciudadana» de la Ley 5/2006, de 2 de mayo, de Ordenación del Territorio y Urbanismo de La Rioja.

32 Artículo 12 «Participación ciudadana» de la Ley 13/2015, de 30 de marzo, de Ordenación Territorial y Urbanística de la Región de Murcia.

33 Artículo 7 «Participación ciudadana» del Decreto Foral Legislativo 1/2017, de 26 de julio, por el que se aprueba el texto refundido de la Ley Foral de Ordenación del Territorio y Urbanismo.

34 Artículo 8 «Principio de participación ciudadana» de la Ley 2/2006, de 30 de junio, de Suelo y Urbanismo.

35 El artículo 2 «Competencias administrativas» de la Ley 5/2014, de 25 de julio, de Ordenación del Territorio, Urbanismo y Paisaje, de la Comunitat Valenciana, establece en su apartado 3, letra c), en el marco del ejercicio de dichas competencias que la ley garantizará «La información y participación ciudadana en los procesos territoriales y urbanísticos». 


\section{Esther Rando Burgos}

instante en que se decide poner en marcha la maquinaria para elaborar o revisar el plan urbanístico ${ }^{36}$.

La ciudadania es quien mejor conoce las necesidades, oportunidades o debilidades del pueblo o ciudad que se decide planificar por ello contar desde el primer momento con ella se entiende más que adecuado, necesario y fundamental.

En este sentido, los mecanismos previstos son los denominados Programas de Participación Ciudadana, incorporados por Comunidades Autónomas como Canarias, Cataluña o País Vasco, o los Planes de Participación Ciudadana recogidos en Navarra o la Comunidad Valenciana, además de otras previsiones como la creación de órganos concretos dirigidos a hacerla efectiva.

Como nexo común, los marcos normativos anteriores incorporan estos instrumentos como fase específica en la propia elaboración de los mismos junto a otras tantas que en la misma tienen lugar, pero además lo hacen, por lo general, con carácter preceptivo, regulando pormenorizadamente cómo ha de llevarse a cabo y lo que se entiende más importante en el momento de gestación del instrumento, de forma que la ciudadanía participa en la elección del modelo de pueblo o ciudad.

Sin ánimo de exhaustividad, se analizan a continuación algunos de los mecanismos señalados, diferenciados por Comunidades Autónomas.

\subsubsection{Canarias: Programa de Participación Ciudadana.}

La Ley 4/2017, de 13 de julio, del Suelo y de los Espacios Naturales Protegidos de Canarias, en adelante LSENC, de manera similar a la tendencia mayoritaria seguida por las Comunidades Autónomas, opta por dedicar un precepto, el artículo 6, a la participación ciudadana, encuadrado en su título preliminar, concretamente en el capítulo II dedicado a los «principios».

Si bien recoge, de forma análoga a otras legislaciones, el derecho de la ciudadanía a participar en la ordenación, ejecución y protección de la legalidad urbanística, entre otros, en los procedimientos de aprobación de los instrumentos de ordenación territorial, urbanística y de los recursos naturales, mediante la formulación de alegaciones, observaciones y propuestas en los periodos de información pública, así como el deber de las Administraciones competentes de adoptar las medidas necesarias para fomentar la más amplia participación

\footnotetext{
36 En relación a los mecanismos de participación ciudadana en el urbanismo, vid. los trabajos de Garcia Valderrey, M.A. 2010. «Los mecanismos de participación ciudadana en materia de urbanismo (1)». Práctica urbanistica. Revista mensual de urbanismo, núm. 92, págs. 7-16; 2010. «Los mecanismos de participación ciudadana en materia de urbanismo (2)». Práctica urbanística. Revista mensual de urbanismo, núm. 93, págs. 10-17; 2010. «Los mecanismos de participación ciudadana en materia de urbanismo (3)». Práctica urbanistica. Revista mensual de urbanismo, núm. 94, págs. 10-16.
} 


\section{Participación ciudadana y urbanismo}

ciudadana, garantizar el acceso a la información y permitir la presentación de iniciativas particulares, da un paso más y contempla la posibilidad de participación en una fase de avance. Concretamente, establece un proceso previo de participación ciudadana de carácter consultivo a través del portal web de la Administración competente para su tramitación, en el que se recabará la opinión de las personas y de las organizaciones, asociaciones y colectivos más representativos potencialmente afectados sobre los problemas que se pretenden solucionar, la necesidad y oportunidad de la regulación, los objetivos que se persiguen y las posibles alternativas.

Su singularidad, sin embargo, viene dada en el apartado 4 del propio artículo 6, al regular, como medio para canalizar las diferentes técnicas de participación, el Programa de Participación Ciudadana. Destacar que, conforme al tenor literal de la ley, no es preceptiva su elaboración, únicamente se indica que «las Administraciones podrán acordar» ${ }^{37}$.

\subsubsection{Cataluña: Programa de Participación Ciudadana y Consejo Asesor Urbanístico.}

Con carácter general, el artículo 8 del Decreto Legislativo 1/2010, de 3 de agosto, por el que se aprueba el texto refundido de la Ley de Urbanismo de Cataluña, en lo sucesivo TRLUC, establece el conjunto de reglas destinadas a garantizar la publicidad y participación en los procedimientos de planeamiento y gestión urbanistica ${ }^{38}$. Además de garantizar, señala que se tiene que fomentar los derechos de información y de participación de la ciudadanía en estos procedimientos, a cuyo efecto faculta a los ayuntamientos para constituir, con carácter voluntario, Consejos Asesores Urbanísticos, como órganos locales de carácter informativo y deliberativo.

Significativo, de igual forma, los medios que enumera para garantizar el derecho de la ciudadanía a consultar y ser informada sobre el contenido de los instrumentos de planeamiento. Entre otros, señala, en el apartado 5, letra a) del citado artículo 8 , que en la información pública de los instrumentos de planeamiento urbanístico, conjuntamente con el plan, se ha de exponer un documento comprensivo de determinadas cuestiones tasadas ${ }^{39}$. También obliga a garantizar el acceso

\footnotetext{
37 El citado precepto dispone: «Al objeto de canalizar las diferentes técnicas de participación, las administraciones podrán acordar un programa de participación ciudadana en el que, atendiendo a las características del municipio, se prevean, al menos: a) Los medios técnicos y materiales necesarios para garantizar que se atienden adecuadamente las solicitudes de información sobre el contenido de la ordenación y de las posibles alternativas. b) La celebración de sesiones abiertas al público explicativas del documento. c) El material divulgativo que facilite su comprensión por la ciudadanía. d) La posibilidad de celebrar consultas populares, de acuerdo con la legislación aplicable».

38 Sobre la participación ciudadana en el planeamiento urbanístico de Cataluña, vid. Martí-Costa, M. y Pybus, M. 2013. «La participación en el urbanismo: los planes de ordenación urbanística municipal en Cataluña». Gestión y Análisis de Politicas Públicas. Nueva Época, núm. 10.
}

39 Entre las que señala, se encuentran, plano de delimitación de los ámbitos sujetos a suspensión de 


\section{Esther Rando Burgos}

telemático al contenido integro de los instrumentos vigentes (artículo 8.5.b) del TRLUC), dar publicidad por medios telemáticos de la convocatoria de información pública en los procedimientos de planeamiento y gestión urbanística y de los acuerdos de aprobación que se adopten en su tramitación (artículo 8.5.c) del TRLUC) y desarrollar por reglamento las formas de consulta y divulgación de los instrumentos urbanísticos, así como los medios de acceso de la ciudadanía a estos instrumentos y la prestación de asistencia técnica para que puedan ser comprendidos correctamente (artículo 8.5.d) TRLUC).

Lo anterior se complementa con la previsión del artículo 59 del TRLUC que alza en obligatorios los mecanismos y medios anteriores, toda vez que deben quedar recogidos en el denominado Programa de Participación Ciudadana, documento que incorpora las actuaciones llevadas a cabo por el correspondiente ayuntamiento a lo largo de todo el procedimiento de formulación y tramitación del plan al objeto de garantizar los ya señalados derechos que el TRLUC reconoce en su artículo 8. El Programa de Participación Ciudadana ha de incorporarse entre los documentos que preceptivamente conforman el contenido documental de los planes de ordenación urbanística municipal, concretamente en la memoria descriptiva y justificativa del plan. Todo ello, de conformidad con las previsiones de los artículos 59.3.a) en relación con el artículo 59.1.a) del TRLUC.

A mayor abundamiento, la disposición final séptima de la TRLUC regula la «Autorización para regular, con carácter supletorio, la participación ciudadana en la elaboración del planeamiento urbanístico general municipal», a cuyo fin «...autoriza al Gobierno, de acuerdo con lo establecido por la disposición final tercera del Decreto legislativo 2/2003, de 28 de abril, por el que se aprueba el texto refundido de la Ley municipal y de régimen local de Cataluña, para regular, con carácter supletorio, si faltan las disposiciones reglamentarias de las corporaciones locales, el despliegue de los aspectos relativos a la participación ciudadana en la elaboración de los planes de ordenación urbanística municipal y de los programas de actuación urbanística municipal».

El Reglamento de la Ley de Urbanismo, aprobado por Decreto 305/2006, de 18 de julio, en coherencia con la importancia dada por el TRLUC, dedica su título II a «De los derechos de información y participación ciudadanas en la actividad urbanística». Particular significancia, a los efectos que ocupan, el capítulo III cuya rúbrica es tajante al referirse al derecho a la participación ciudadana. Como mecanismos para su materialización, entre otros, recoge dos que se encarga de regular detalladamente, los Programas de Participación Ciudadana en el proceso de planeamiento y los Consejos Asesores Urbanísticos.

licencia y de tramitación de procedimientos, así como concreción del plazo de suspensión y alcance de las licencias y tramitaciones que se suspenden o un resumen de alcance de sus determinaciones que para el caso de revisión o modificación del instrumento de planeamiento urbanístico, debe incluir plano de identificación de los ámbitos en los que la ordenación propuesta altera la vigente y resumen del alcance de la alteración. 


\section{Participación ciudadana y urbanismo}

El Programa de Participación Ciudadana es uno de los actos preparatorios para la formulación de las figuras de planeamiento urbanístico. Así lo fija el artículo 101.1 del Reglamento, al enumerar las actuaciones preparatorias e incorporar entre éstas, en su letra b), la aprobación y publicación del Programa de Participación Ciudadana en la formulación y tramitación del plan. Por su parte, en su artículo 105 concreta que podrá acordarse en cualquier momento anterior al acuerdo de aprobación inicial del plan urbanístico, deviniendo en obligatoria en los de formulación o revisión del Plan de Ordenación Urbanística Municipal, pudiendo, en este caso, acordarse previa o simultáneamente a la publicación del avance del mismo.

Estas previsiones se perfeccionan en el artículo 22 del Reglamento de la Ley de Urbanismo catalana que se centra en dos cuestiones concretas, por un lado, definir este instrumento y por otro, determinar el contenido sustantivo que ha de conformarlo, distinguiendo para ello la fase concreta de elaboración/tramitación del instrumento de planeamiento urbanístico.

El Programa de Participación Ciudadana, de conformidad con el artículo 22.2 del Reglamento, es el documento que expresa las medidas y actuaciones previstas para facilitar tanto la divulgación y la comprensión de los objetivos y del contenido de los trabajos de planeamiento, como la formulación de alegaciones, sugerencias o propuestas alternativas en el marco del trámite e información pública.

El programa puede referirse a tres fases concretas, lo que determinará su contenido. La fase previa al periodo de información pública es la fundamental y la que mayor valor puede aportar a una efectiva participación ciudadana ya que en la misma se concreta el modelo a adoptar por el plan urbanístico. En esta primera fase, el Programa de Participación Ciudadana está integrado por tres mecanismos:

- Acciones de información y comunicación dirigidas a difundir el acuerdo de iniciar el planeamiento y facilitar los datos necesarios para dar a conocer su alcance y características, a través de la publicación y exposición al público del documento de avance mediante actos informativos, conferencias o la presentación de estudios previos.

- Canales de participación dirigidos a definir los instrumentos que se pondrán a disposición de la ciudadanía y las instituciones para recoger sus opiniones, facilitar el debate y la presentación de propuestas. Para ello propone la realización de encuestas, entrevistas, debates en grupos o talleres de propuestas.

- Sistema de recogida y análisis de las aportaciones realizadas y la presentación del informe de resultados del proceso.

Las dos fases restantes se centran en el periodo de información pública, distinguiendo el contenido que ha de contener el programa según se trate de la información pública en sentido propio o la fase posterior a la misma. Así, en la fase 


\section{Esther Rando Burgos}

de información pública, el Programa de Participación Ciudadana se centra en articular mecanismos de información sobre la ordenación propuesta y mecanismos dirigidos a dar a conocer la apertura de dicho periodo, así como la recogida de alegaciones y propuestas habilitando medios y espacios adecuados. En la última fase, como se ha indicado, posterior a la fase de información pública, el programa debe incorporar tres cuestiones: un informe de valoración de las propuestas e iniciativas presentadas en todas las fases de elaboración, mecanismos de publicidad del contenido del informe de valoración y el acuerdo de aprobación del Programa de Participación Ciudadana mediante edicto en el diario o boletín que corresponda.

Por su parte, en el marco organizativo, los Consejos Asesores Urbanísticos, regulados en el artículo 24 del Reglamento, son órganos cuya constitución queda a discreción de los ayuntamientos, con facultades informativas y deliberativas. Sin carácter exhaustivo, el Reglamento enumera algunas de las funciones que pueden desarrollar como: proponer medidas y actuaciones para incluirlas en el Programa de participación ciudadana y hacer el seguimiento de su puesta en práctica; formular y plantear criterios y alternativas de ordenación; considerar las propuestas del planeamiento para garantizar los objetivos del desarrollo urbanistico sostenible; opinar sobre las alegaciones presentadas; estudiar, proponer y seguir las medidas y las actuaciones a emprender para fomentar la participación ciudadana en la tramitación de las figuras de planeamiento derivado y de instrumentos de gestión cuando consideren que su trascendencia lo justifique.

La composición de estos consejos vendrá dada por las personas integrantes designadas por los ayuntamientos, apuntándose por el Reglamento, a modo de ejemplo, en el artículo 24.2 «...representantes de otras administraciones públicas, corporaciones, asociaciones y otras instituciones de la sociedad civil, así como expertos en urbanismo, vivienda, medio ambiente y otras materias relacionadas con el urbanismo».

\subsubsection{Navarra: Plan de Participación.}

La Comunidad Foral de Navarra también apuesta de manera decidida por hacer efectiva la participación ciudadana en la conformación de sus instrumentos de planeamiento urbanístico. De esta forma, el artículo 7 del Decreto Foral Legislativo 1/2017, de 26 de julio, por el que se aprueba el texto refundido de la Ley Foral de Ordenación del Territorio y Urbanismo, para sucesivas menciones TRLOTUN, establece la importancia de llevar a cabo la mayor participación ciudadana, garantizando los derechos de información.

Pero tras esta generalidad, señala cuestiones concretas para su materialización. De esta forma, por un lado, «...cualquiera de los instrumentos de ordenación territorial y urbanísticos contemplados en esta ley será sometido a un período no menor de veinte dias de participación ciudadana, mediante la exposición pública y, en su caso, audiencia a las entidades locales, previamente a su aprobación definitiva» 


\section{Participación ciudadana y urbanismo}

(artículo 7.2 del TRLOTUN). Sin embargo, lo que reviste mayor significancia es la previsión del artículo 7.3 del propio TRLOTUN que enumera el conjunto de instrumentos de ordenación territorial (Estrategia Territorial de Navarra, Planes de Ordenación Territorial, Planes Directores de Acción Territorial y Planes y Proyectos Sectoriales de Incidencia Supramunicipal) ${ }^{40}$ y urbanística, entre estos últimos señala expresamente, los Planes Generales Municipales, los Planes Parciales, los Planes Especiales y los Planes Especiales de Actuación Urbana, junto a las modificaciones de planeamiento que planteen actuaciones de nueva urbanización, que «...contarán con la participación real y efectiva de la ciudadanía en su elaboración y revisión de conformidad con los principios y derechos establecidos en el Título IV de la Ley Foral 11/2012, de 21 de junio, de la Transparencia y del Gobierno Abierto, mediante un proceso de participación ciudadana de carácter consultivo previo a la aprobación inicial del instrumento».

Este proceso de participación se instrumenta mediante un Plan de Participación cuyo contenido, como enumera el apartado 4 del propio artículo 7 del TRLOTUN, al menos, debe precisar: la identificación de los agentes sociales y ciudadanos interesados por el planeamiento; resúmenes de las propuestas de ordenación más importantes para facilitar la difusión y comprensión ciudadana; la Memoria de viabilidad y sostenibilidad económica; la metodología y herramientas de difusión y participación, que incluirán tanto sistemas de participación on-line como sesiones explicativas sobre el contenido de la ordenación futura y de las alternativas valoradas; y finalmente, las conclusiones valoradas del proceso de participación desarrollado.

De manera precisa, y centrados en el instrumento de planeamiento general previsto por el TRLOTUN, el Plan General Municipal, el artículo 58 al regularlo, y tras distinguir en su composición entre la Estrategia y Modelo de Ocupación Territorial (previo a la formulación del Plan Urbanístico Municipal, en el que se contiene «la definición de la estrategia de desarrollo del municipio, sus prioridades, modelo de crecimiento, aprovechamiento de sus recursos y superación de sus debilidades, a los efectos de garantizar la adecuación del modelo municipal de ocupación del territorio al modelo de ordenación del territorio de su ámbito definido por los instrumentos de ordenación territorial vigentes, así como con las políticas territoriales y ambientales de la Comunidad Foral») y el Plan Urbanístico Municipal (propiamente el documento urbanístico que «define los aspectos propios de la ordenación y régimen del suelo del municipio»), enumera entre la documentación preceptiva que ha de integrar el primero unas conclusiones valoradas del proceso de participación ciudadana.

\footnotetext{
40 Para una visión detallada de los procedimientos de tramitación y elaboración de los instrumentos de planificación territorial por las diferentes Comunidades Autónomas y, en particular, en el caso de Navarra, vid. Rando Burgos, E. 2019. Legislación e instrumentos de la ordenación del territorio en España. Madrid: Editorial lustel.
} 


\section{Esther Rando Burgos}

Nuevamente el artículo 71 del TRLOTUN, dedicado a la tramitación del Plan General Municipal, enfatiza en la importancia del mismo, precisando que ha de llevarse a cabo en dos momentos: en la tramitación de la Estrategia y Modelo de Ordenación del Territorio y en la tramitación del Plan Urbanístico Municipal, pero además precisa que dicho Plan de Participación habrá de ser adoptado por el ayuntamiento respectivo con carácter previo al inicio de la redacción del Plan General Municipal. Esta cuestión se entiende como clave para sentar de antemano unas bases y un cronograma que posibilite su ulterior cumplimiento.

\subsubsection{País Vasco: Programa de Participación Ciudadana y Consejo Asesor del Planeamiento.}

Una de las primeras cuestiones que por su significancia merecen especial atención es la diferenciación que la Ley $2 / 2006$, de 30 de junio, de Suelo y Urbanismo de País Vasco, en adelante LSUPV, realiza entre participación ciudadana e información pública.

De esta forma, al enunciar los principios generales del urbanismo, lo sustenta en siete pilares, regulados correlativamente en los artículos 3 a 9 de la LSUPV: desarrollo sostenible, subordinación al interés público, competencia del planeamiento urbanístico, concertación, coherencia de la ordenación urbanística, participación ciudadana e información pública.

El concepto que la LSUPV aporta de estos dos últimos principios, aproximan al diferente pero interrelacionado protagonismo que ambos asumen en el urbanismo. De esta forma, el principio de participación ciudadana se define como:

«1. La ordenación urbanistica se formulará, tramitará, aprobará y ejecutará favoreciendo y facilitando la participación, en todas sus formas, de las personas físicas o jurídicas, con garantía de las expresamente previstas en esta ley.

2. El principio de participación comportará el derecho a:

a) Comparecer como interesado, sin necesidad de acreditar legitimación especial, en los procedimientos de tramitación del planeamiento, de ejecución y de disciplina urbanística.

b) Acceder y obtener copia, en la forma que se determine por cada administración pública de la documentación que obre en los archivos de las administraciones públicas competentes, sin otras limitaciones que las generales establecidas en las leyes.

c) Ejercer en vía administrativa y judicial, sin necesidad de legitimación especial, las acciones pertinentes para exigir de las administraciones públicas y de los sujetos privados el cumplimiento de la legislación y la ordenación urbanística». 


\section{Participación ciudadana y urbanismo}

Por su parte, para la LSUPV, el principio de información pública como informador del urbanismo, comporta:

«1. La totalidad de la documentación integrante del planeamiento en vigor tendrá carácter público. Para garantizar su publicidad, las administraciones públicas competentes, además de los anuncios y publicaciones oficiales, deberán:

a) Realizar y mantener ediciones actualizadas de los planes y ponerlas a disposición de la ciudadanía.

b) Insertar íntegramente los planes, actualizando su contenido, en un lugar de la red telemática de que dispongan y que sea de acceso libre.

c) Expedir, a solicitud de cualquier persona, certificaciones o copias certificadas de la ordenación urbanística aplicable a unos inmuebles concretos.

2. Todas las personas físicas o jurídicas podrán actuar de acuerdo con la información que se consigne en los documentos expedidos conforme a la letra c) del párrafo anterior. La confianza en la veracidad y corrección de dicha información se presumirá legítima a los efectos, en su caso, de la responsabilidad patrimonial de las administraciones públicas. En caso de error, los documentos expedidos no vinculan a la Administración, sin perjuicio de las indemnizaciones procedentes por daños y perjuicios.

3. En la tramitación de los documentos de planeamiento, los ayuntamientos procurarán la información pública de sus contenidos, proyectos y previsiones mediante instrumentos de información indicativos y comparativos del estado actual y la imagen futura prevista por sus determinaciones».

El principio general de participación ciudadana se materializa en el articulado de la ley, entre otros, cuando al enumerar el contenido documental mínimo del Plan General de Ordenación Urbana ${ }^{41}$, el artículo 62.1.a) de la LSUPV, señala que en el documento de Memoria informativa y justifica se debe incorporar «toda la información que contenga los elementos de juicio para el ejercicio de la potestad de planeamiento, y describir el proceso de formulación y selección de alternativas para la adopción de decisiones, el análisis de las alegaciones, sugerencias y reclamaciones formuladas a título de participación ciudadana, y la justificación de las soluciones asumidas». De análoga forma, se establece para los Planes Parciales en el artículo 68.a) de la LSUPV.

41 Integrado, conforme al citado precepto por los siguientes documentos: memoria informativa y justificativa; memoria justificativa de cumplimiento del informe preliminar de impacto ambiental; planos de información; planos de ordenación estructural; planos de ordenación pormenorizada; y estudio de viabilidad económico-financiera. 


\section{Esther Rando Burgos}

Ahora bien, la apuesta de País Vasco por una efectiva participación ciudadana en la conformación del urbanismo no queda en las previsiones anteriores. Una de las primeras cuestiones que se ocupa la LSUPV de fijar al regular la tramitación y aprobación del planeamiento, es la previsión de que junto al acuerdo de formulación del correspondiente plan o instrumento urbanístico se incorpore el Programa de Participación Ciudadana que se llevará a cabo en el proceso de su elaboración, tramitación y aprobación (artículo 84.4 de la LSUPV). Cuestión que reitera y concreta en el artículo 108 dedicado expresamente al «Programa de participación ciudadana en el plan general», conforme al cual:

«El acuerdo municipal de inicio de la formulación, modificación o revisión de cualquier figura de planeamiento de ordenación estructural deberá estar acompañado de un programa de participación ciudadana en el que, según las características del municipio, se establecerán los objetivos, estrategias y mecanismos suficientes para posibilitar a los ciudadanos y ciudadanas y entidades asociativas el derecho a participar en el proceso de su elaboración. Entre estos mecanismos figurarán:

a) Sesiones abiertas al público explicativas del contenido del avance, en especial de las decisiones estratégicas de construcción de la ciudad y las posibles alternativas presentadas en la tramitación del expediente.

b) Posibilidad de celebrar consulta popular municipal, según la regulación establecida en la legislación básica de régimen local, en caso de graves controversias ciudadanas sobre alguno de los aspectos incluidos en el plan.

c) Material divulgativo, que deberá prepararse junto con los documentos legalmente exigidos para los instrumentos urbanísticos, al objeto de facilitar su difusión y comprensión».

Asimismo, a nivel orgánico, y de manera análoga a Cataluña, regula la figura del Consejo Asesor del Planeamiento Urbanístico, si bien su principal diferencia respecto a esta Comunidad Autónoma, radica en que en determinados municipios su existencia sí resulta obligatoria. El artículo 109 de la LSUPV define el Consejo Asesor del Planeamiento Municipal como el órgano local de carácter consultivo y deliberante para el cumplimiento de las funciones de concertación social en relación con el procedimiento de formulación, tramitación y aprobación de los planes urbanísticos, de existencia obligatoria en los municipios que tengan la competencia, propia o delegada, para la aprobación definitiva de planes generales ${ }^{42}$.

42 Ostentan la competencia para la aprobación definitiva de los planes generales, conforme al artículo 91 de la LSUPV, los ayuntamientos en los municipios con población superior a 7000 habitantes. En los restantes supuestos, serán competentes las diputaciones forales, sin perjuicio de la posibilidad contemplada en el apartado 8 del propio artículo 91, que faculta a las diputaciones forales para delegar dicha competencia a municipios con población igual o inferior a 7000 habitantes o entidades 


\section{Participación ciudadana y urbanismo}

Las principales funciones del Consejo Asesor vienen dadas por el conocimiento de cuantos estudios, programas, directrices y líneas de actuación elaboren o establezcan las Administraciones responsables de la formulación del planeamiento general del municipio para coadyuvar a su elaboración, e informará, en todo caso, una vez iniciada la redacción técnica del plan general. Su intervención se manifiesta en documentos de análisis de las cuestiones que tome en consideración, que podrán contener propuestas y alternativas de carácter no vinculante para las Administraciones públicas, las cuales, para el caso de no ser atendidas por la Administración que apruebe el planeamiento en la resolución de aprobación definitiva del mismo, deben ser contestadas motivadamente.

Por último, el funcionamiento, la constitución y disolución así como la composición de este órgano se determinarán mediante reglamento municipal, si bien el Reglamento fija algunas reglas como su presidencia que será ostentada por la alcaldía del municipio o la presencia en el mismo «...del movimiento asociativo vecinal $y$ de representantes de entidades $u$ organizaciones dedicadas a la protección y defensa medioambiental que intervengan en el término municipal».

\subsubsection{Comunidad Valenciana: Plan de Participación Pública.}

De análoga manera, la Comunidad Valenciana también apuesta de manera activa por hacer efectiva la participación ciudadana en la elaboración de sus instrumentos de planeamiento urbanístico. Con esta finalidad, la Ley 5/2014, de 25 de julio, de Ordenación del Territorio, Urbanismo y Paisaje, de la Comunitat Valenciana, en sucesivas menciones LOTUPCV, instaura un concreto mecanismo que denomina Plan de Participación Pública ${ }^{43}$.

Regulado en el artículo 51.4.C) de la LOTUPCV, precepto dedicado a «Consultas a las administraciones públicas afectadas y elaboración del documento de alcance del estudio ambiental y territorial estratégico», el Plan de Participación Pública es presentado como el documento que integrado en el documento de alcance, ha de identificar las Administraciones públicas afectadas y al público interesado en el plan o programa y las modalidades o amplitud de información y consulta. Dos cuestiones centran la regulación de esta figura. En primer lugar, debe contener, al menos, la información pública mediante anuncio en el Diario Oficial de la Generalitat Valenciana" y en un medio de comunicación social de prensa escrita de gran difusión y poner la documentación a disposición del público. En segundo

públicas supramunicipales de los que aquellas sean miembros, siempre que unos y otros dispongan de servicios técnicos suficientes para tal cometido y acepten la delegación. En cualquier caso, con carácter previo a la aprobación definitiva debe emitirse informe de la Comisión de Ordenación del Territorio del País Vasco.

43 Sobre los Planes de Participación Pública y la propia participación como elemento clave en la gobernanza, centrado en la Comunidad Valenciana, vid. Farinós Dasí, J. y Sánchez Cabrera, J.V. 2010. «Cambios recientes en los instrumentos de la política territorial en la Comunidad Valenciana. Limites al renovado papel del paisaje, de la evaluación y de la participación en la ordenación del territorio». Cuadernos Geográficos, núm. 87, págs. 45-64. 


\section{Esther Rando Burgos}

lugar, para el caso de revisiones de planes generales de ordenación estructural y de modificaciones que supongan cambios de clasificación de suelo que alteren el modelo territorial del municipio o en la calificación del suelo que incrementen su aprovechamiento, el Plan de Participación Pública incluirá, además y al menos, la celebración de sesiones explicativas abiertas al público sobre el contenido de la ordenación futura y las alternativas presentadas, la elaboración de resúmenes e infografias de las propuestas de ordenación más importantes para facilitar la difusión y comprensión ciudadana de la ordenación, así como memoria de viabilidad económica preceptiva, elaborada sobre la base de estudios de mercado rigurosos y acreditados por sociedades de tasación homologadas por entidades públicas con competencia para ello o por entidades análogas de otros países ${ }^{44}$.

De igual forma, establece que «se permitirá la participación telemática desde un fórum o espacio habilitado donde el documento sea abierto a la ciudadanía y en el que se permita hacer aportaciones». El empleo de medios telemáticos, cada vez de mayor uso, es sin duda un gran aliado que facilita y favorece de manera importante la participación ciudadana.

Significativo destacar que dicho plan es el resultado del proceso de participación pública que la LOTUPCV establece como preceptivo en la tramitación de los planes o programas que requieren evaluación ambiental y territorial estratégica ${ }^{45}$. Entre las actuaciones que con carácter sucesivo se encarga de regular el artículo 49.1 de la LOTUPCV, se establece, en la letra e), el sometimiento de la versión preliminar del plan o programa y del estudio ambiental y territorial estratégico al proceso de participación pública, información pública y consultas.

Además, la correspondiente documentación del plan o programa que se tramite debe ser accesible al público, pudiendo ser consultada durante y una vez superada la fase correspondiente del procedimiento. A tal efecto, el órgano promotor adoptará las medidas necesarias para que sean accesibles por medios electrónicos un conjunto de documentos entre los que se encuentra el documento de participación pública.

Una vez elaborada la versión inicial del plan o programa, junto con su estudio ambiental y territorial estratégico y el resto de documentos exigibles por la normativa sectorial, será sometido a participación pública mediante la ejecución de las acciones que se hayan definido en el Plan de Participación Pública, finalizado el

\footnotetext{
44 Sobre la participación ciudadana en el ámbito de la Comunidad Valenciana, vid. Beunza Ibáñez, H. y Alfonso Tormo, C. 2017. «Participación ciudadana en instrumentos de planeamiento en la Comunidad Valenciana». Práctica urbanística. Revista mensual de urbanismo, núm. 144. Los autores destacan los recientes impulsos a mecanismos de participación ciudadana en la toma de decisiones frente a su entendimiento hasta tiempos recientes limitado a la publicación de anuncios en boletines oficiales y diarios y la recepción de alegaciones por parte de las partes «interesadas».

45 Cuestión regulada en el artículo 46 de la LOTUPCV, dedicado a «Planes y programas que serán objeto de la evaluación ambiental y territorial estratégica».
} 


\section{Participación ciudadana y urbanismo}

cual y en los términos fijados en el artículo 51.4.c) de la LOTUPCV, será elaborado el documento de participación pública en el que se sintetizarán sus resultados y se justificará cómo se toman en consideración en una propuesta de plan o programa.

Como particularidad, entre las modificaciones incorporadas por la LOTUPCV por la Ley 1/2019, de 5 de febrero, el cuerpo legal concreta determinados grupos de población que han de incorporarse dentro del Plan de Participación Pública. En concreto, el apartado 10.3. del anexo III «Criterios y reglas para la planificación con perspectiva de género» establece que «Dentro del plan de participación pública del artículo 53.1 de la ley y del anexo I, hay que incorporar entre las personas interesadas para el proceso participativo a los sectores de población correspondientes a los perfiles resultantes del análisis demográfico del apartado 2 de este anexo. Se fomentará, especialmente, la participación de las mujeres en la elaboración de planes y proyectos urbanos con una doble función: incorporar al debate su forma de vivir la ciudad y disponer de su compleja visión formada desde la vinculación con otros grupos sociales que dependen de ellas, y que hace que su participación sea de especial interés en la ordenación del detalle de los planes y los proyectos de urbanización y de obra pública. Debe justificarse expresamente la participación de las personas de diferentes grupos sociales, los resultados de este estudio participativo y la incorporación a los documentos urbanísticos».

\section{CONCLUSIONES}

A modo de conclusiones o reflexiones finales, es adecuado perfilar determinadas cuestiones. En primer lugar, esencial, la concreción que entre información pública y participación ciudadana en los procedimientos de elaboración y tramitación de instrumentos de planeamiento urbanístico tiene lugar, lo que a día de hoy es una realidad recogida por las diferentes legislaciones urbanisticas. La información pública es un trámite preceptivo y esencial que forma parte del procedimiento de tramitación de los planes urbanísticos, no quedando por tanto a discreción del legislador su debido y obligado cumplimiento, además de constituir el cauce con el que tradicionalmente se ha venido materializando la participación ciudadana. Aun reconociendo tal carácter, paulatinamente, se vienen generando nuevos cauces y mecanismos de participación ciudadana destinados a favorecer y fomentar una efectiva y real implicación de la ciudadanía en la definición del modelo urbano, para lo que se entiende adecuado y necesario que se efectúe en un momento muy anterior al de la tramitación del plan (momento en que ya está concretado este modelo), sin perjuicio de que la misma se extienda durante el procedimiento de tramitación. Sin embargo, no se está, por lo general, ante un trámite preceptivo, salvo en determinadas Comunidades Autónomas que sí lo instrumentalizan a través de Planes o Programas de Participación Ciudadana, integrándolo con carácter preceptivo como fase a la que necesariamente se ha de dar debido cumplimiento. 


\section{Esther Rando Burgos}

Anima, por tanto, observar que se impone progresivamente con fuerza la necesidad de implementar cauces dirigidos a una efectiva participación ciudadana en la elaboración y no sólo tramitación de los instrumentos. Lo que enlaza con la necesaria transparencia que en la elaboración de normas, carácter que se predica de los instrumentos de planeamiento urbanístico, con gran repercusión en la vida de los ciudadanos, debe tener lugar. Paulatinamente, y aunque por el momento son casos todavía puntuales, se atisba como se está pasando de enunciar la participación ciudadana como principio general y su materialización únicamente a través de la información pública, al establecimiento de otros mecanismos concretos destinados a su efectiva puesta en marcha e instaurándose en una fase propia del procedimiento de elaboración de los planes.

Pero a la postre, esta cuestión tiene una segunda lectura, la transparencia en la definición del modelo urbano a través de la técnica planificadora con la incorporación de la ciudadanía en su concreción, permitirá alcanzar una importante legitimidad a los planes urbanísticos por la elevada repercusión que los mismos tienen sobre la vida de los ciudadanos, favoreciendo su consecución. Entre otras, por una sencilla razón, se tendrá una visión más real del medio que se planifica y se adoptarán decisiones más eficaces. Es la ciudadanía de un pueblo o ciudad la que mejor conoce sus oportunidades, debilidades, fortalezas o amenazas y por tanto, un valiosísimo componente que no sólo se ha de tener presente sino ponerlo en valor, aprovechando las ventajas que puede aportar. 


\section{Participación ciudadana y urbanismo}

\section{BIBLIOGRAFÍA}

Alarcón Sotomayor, L. 2017. «El procedimiento administrativo». En Rebollo Puig, M. y Vera Jurado, D. (dirs.) Derecho Administrativo. Tomo II, Rebollo Puig, M. y Carbonell Porras, E. (coords.) Régimen juridico básico y control de la Administración. Madrid: Editorial Tecnos, págs. 17-68.

Beunza Ibáñez, H. y Alfonso Tormo, C. 2017. «Participación ciudadana en instrumentos de planeamiento en la Comunidad Valenciana». Práctica urbanistica. Revista mensual de urbanismo, núm. 144.

Chinchilla Peinado, J.A. 2016. «La participación ciudadana en el urbanismo: ¿mito o realidad?». En Gifreu i Font, J., Bassols Coma, M. y Menéndez Rexach, Á. (dirs.) El derecho a la ciudad y el territorio: estudios en homenaje a Manuel Ballbé Prunés. Madrid: Instituto Nacional de Administración Pública, págs. 232-246.

Farinós Dasí, J. y Sánchez Cabrera, J.V. 2010. «Cambios recientes en los instrumentos de la política territorial en la Comunidad Valenciana. Limites al renovado papel del paisaje, de la evaluación y de la participación en la ordenación del territorio». Cuadernos Geográficos, núm. 87, págs. 45-64.

Fernández Ramos, S. y Pérez Monguió, J.M. 2017. El Derecho al Acceso a la Información Pública en España. Thomson Reuteurs Aranzadi.

García Macho, R. 2011. «La participación ciudadana en la ordenación urbanística y admisión de proyectos de obras públicas». En Sánchez Blanco, Á., DomínguezBerrueta de Juan, M.Á., Rivero Ysern, J.L. (coords.). El nuevo derecho administrativo: libro homenaje al Profesor Dr. Enrique Rivero Ysern. Salamanca: Ratio Legis Librería Jurídica, págs. 179-185.

Garcia Valderrey, M.A. 2010. «Los mecanismos de participación ciudadana en materia de urbanismo (1)». Práctica urbanistica. Revista mensual de urbanismo, núm. 92, págs. 7-16.

García Valderrey, M.A. 2010. «Los mecanismos de participación ciudadana en materia de urbanismo (2)». Práctica urbanistica. Revista mensual de urbanismo, núm. 93, págs. 10-17.

García Valderrey, M.A. 2010. «Los mecanismos de participación ciudadana en materia de urbanismo (3)». Práctica urbanistica. Revista mensual de urbanismo, núm. 94, págs. 10-16.

Martí-Costa, M. y Pybus, M. 2013. «La participación en el urbanismo: los planes de ordenación urbanística municipal en Cataluña». Gestión y Análisis de Politicas Públicas. Nueva Época, núm. 10. 


\section{Esther Rando Burgos}

Mozo Amo, J. 2015. «El urbanismo y la participación ciudadana». Encuentros multidisciplinares, Vol. 17, núm. 50. Ejemplar dedicado a: Urbanismo y Organización del Territorio en clave multidisciplinar, págs. 23-30.

Ponce Solé, J. y Capdeferro Villagrasa, Ó. 2017. «Buen gobierno urbano, transparencia y participación ciudadana». En VAQUER CABALLERÍA, M. Ejemplar dedicado a: La ley estatal de suelo, 10 años después. Práctica urbanistica. Revista mensual de urbanismo, núm. 146.

Rando Burgos, E. 2019. Legislación e instrumentos de la ordenación del territorio en España. Madrid: Editorial lustel.

Rando Burgos, E. 2020. Régimen Juridico de la Gestión Territorial. Valencia: Editorial Tirant lo Blanch.

Razquin Lizarraga, M.M. 2015. El derecho de acceso a la información pública: teoría y práctica, en especial, para las entidades locales. Guipuzkoa: Instituto Vasco de Administración Pública.

Tardío Pato, J.A. 2006. «El principio constitucional de audiencia del interesado y el trámite del artículo 84 de la Ley 30/1992». Revista de Administración Pública, núm. 170, págs. 93-142.

Tardio Pato, J.A. 2017. «Alegaciones, audiencia y participación y de los interesados». En Fernández Ramos, S., Valero Torrijos, J. y Gamero Casado, E. (dirs.) Tratado de Procedimiento Administrativo Común y Régimen Juridico Básico del Sector Público. Valencia: Editorial Tirant lo Blanch, págs. 1554-1638.

Tardío Pato, J.A. 2018. «Los límites al principio de la mayoría no sólo derivados del Estado de Derecho sino también del propio Estado Democrático: la denominada Ley catalana de autodeterminación como ejemplo». Revista Española de Derecho Administrativo, núm. 189, págs. 93-126.

Tardío Pato, J.A. 2019. «Comentario al artículo 43, de la Ley Valenciana 2/2015». En Díez Sánchez, J.J. y García Macho, R. (coords.) Comentarios a la Ley 2/2015, de 2 de abril, de Transparencia, Buen Gobierno y Participación Ciudadana en la Comunitat Valenciana. Madrid: Editorial Reus.

Tolivar Alas, L. 2010. «Principio de participación». En Santamaría Pastor, J.A. (dir.) Los principios jurídicos del derecho administrativo. Madrid: Editorial La Ley, págs. 945-979. 